\title{
COMPARISON OF ANALGESIC EFFECT OF INTRA-ARTICULAR BUPRENORPHINE AND MORPHINE FOLLOWING ARTHROSCOPIC SURGERY OF KNEE
}

\author{
Shashidhar Gowdra Sugandarajappa1, Rashmi N. R2, Sumitha C. S3, Suresh Chengode 4 \\ ${ }^{1}$ Assistant Professor, Department of Anaesthesia \& Pain Relief, Kidwai Memorial Institute of Oncology, Bengaluru. \\ ${ }^{2}$ Assistant Professor, Department of Anaesthesia \& Pain Relief, Kidwai Memorial Institute of Oncology, Bengaluru. \\ ${ }_{3}^{3}$ Assistant Professor, Department of Anaesthesia \& Pain Relief, Kidwai Memorial Institute of Oncology, Bengaluru. \\ 4 Professor, Department of Anaesthesia, Amrita Institute of Medical Sciences, Kochi.
}

\section{ABSTRACT}

\section{BACKGROUND AND AIMS}

Pain after orthopaedic surgery depends on the site and extent of surgery and the preoperative use of analgesics by the patient. Arthroscopic procedures are routinely performed on outpatient basis and have spared patients large incisions and decreased morbidity compared with open incisions, but has not eliminated pain. At present several techniques are available to treat pain following arthroscopic surgeries; these include the use of opioids, local anaesthetics, NSAIDs, corticosteroids, clonidine and cryotherapy. Here, we compared the analgesic effect of intra-articular administration of morphine, buprenorphine and placebo following arthroscopic surgery of knee.

\section{METHODS}

A prospective, randomised, placebo-controlled double-blind comparative study conducted in 60 patients of either sex who underwent arthroscopic surgery of knee; between the age group of 18 and 65 years and of ASA class I and II physical status we re included in the study. Patients were randomly assigned equally to one of the 3 groups of 20 each by a sealed envelope method. The groups were Group A - Patients receiving IA Buprenorphine $100 \mathrm{mcg}$ in $20 \mathrm{~mL}$ normal saline. Group B - Patients receiving IA Morphine $3 \mathrm{mg}$ in $20 \mathrm{~mL}$ normal saline. Group C - Patients receiving IA $20 \mathrm{~mL}$ normal saline as placebo. Parameters monitored were degree of analgesia along with haemodynamic parameters and side effects. Data were analysed using student's t-test for continuous variables and Chi-Square test.

\section{RESULTS}

We found that $100 \mathrm{mcg}$ buprenorphine when injected intra-articularly produced good and comparable postoperative pain control and reduced supplementary analgesic requirement when compared to other groups.

\section{CONCLUSION}

In summary, this study demonstrated that for eight hours postoperatively 100 mcg buprenorphine provided superior postoperative analgesia to that of $3 \mathrm{mg}$ morphine.

\section{KEYWORDS}

Intraarticular, Analgesia, Opioids, Arthroscopy.

HOW TO CITE THIS ARTICLE: Sugandarajappa SG, Rashmi NR, Sumitha CS, et al. Comparison of analgesic effect of intraarticular buprenorphine and morphine following arthroscopic surgery of knee. J. Evolution Med. Dent. Sci. 2016;5(60):4175-4180, DOI: $10.14260 /$ jemds/2016/953

\section{INTRODUCTION}

Pain is a common human experience, a symptom frequently encountered in clinical practice that is usually associated with actual or impending tissue damage. "Failure to relieve pain is morally and ethically unacceptable." Adequate pain relief could be considered a basic human right. Pain is not a straightforward sensory "perception." It is an "experience" as the physiological sensation is inseparable from the associated emotional distress.

Pain after orthopaedic surgery depends on the site and extent of surgery.

Financial or Other, Competing Interest: None.

Submission 18-06-2016, Peer Review 13-07-2016,

Acceptance 20-07-2016, Published 27-07-2016.

Corresponding Author:

Dr. Shashidhar Gowdra Sugandarajappa,

Assistant Professor,

Department of Anaesthesia \& Pain Relief,

Kidwai Memorial Institute of Oncology,

Dr. M. H. Marigowda Road,

Bengaluru-560029.

E-mail: drshashi_2007@yahoo.co.in

DOI: $10.14260 /$ jemds/2016/953
Arthroscopic procedures are routinely performed on outpatient basis and have spared patients large incisions and decreased morbidity compared with open incisions, but has not eliminated pain. At present, several techniques are available to treat pain following arthroscopic surgeries; these include the use of opioids (Either providing peripherally or centrally mediated analgesia), local anaesthetics, nonsteroidal anti-inflammatory drugs, corticosteroids, clonidine and cryotherapy. Common methods of postoperative pain management in hospitalized patients (Parenteral or extradural opioids) appear to be unsuitable for outpatient surgery. The evidence of synovial opioid receptors supports the use of Intra-articular (IA) opioids to achieve a peripheral opiate receptor-mediated analgesia. A number of such studies have demonstrated effective and prolonged analgesia from small Intra-articular (IA) doses of morphine.1-8 In contrast, other investigators have failed to demonstrate an analgesic effect of IA morphine. ${ }^{9-15}$

Morphine is the most frequently used opioid analgesic. Buprenorphine is a partial agonist with a higher receptor affinity than morphine, which accounts for intense and 
prolonged analgesia. Various direct and indirect measures had evaluated the effects of intra-articular application of opioids on postoperative pain relief.

Here, we sought to compare the analgesic efficacy of intraarticular administration of morphine and buprenorphine following arthroscopic surgery of knee.

\section{MATERIAL AND METHODS}

The study designed was a prospective, randomised, placebo controlled, double blind comparative study conducted at Amrita Institute of Medical Sciences and Research Centre, Kochi; 60 patients of either sex, who underwent arthroscopic surgery of knee; between the age group of 18 and 65 years and of ASA class I and II physical status were included in the study. Patients of ASA III and IV physical status and patients on chronic medications were excluded from the study.

After approval from the Hospital Ethics Committee, 60 patients were randomly assigned equally to one of the three groups of 20 each by a sealed envelope method.

Group A - Patients receiving IA Buprenorphine $100 \mathrm{mcg}$ in $20 \mathrm{~mL}$ normal saline.

Group B - Patients receiving IA Morphine $3 \mathrm{mg}$ in $20 \mathrm{~mL}$ normal saline.

Group C - Patients receiving IA $20 \mathrm{~mL}$ normal saline as placebo.

The randomized assignment was sealed in an envelope and handed over to a senior anaesthesia technician, who would verify the group on the day of surgery and prepared the bolus solution of drug with $20 \mathrm{~mL} 0.9 \%$ normal saline under aseptic precautions. At the conclusion of surgery and after removal of the arthroscope, one of the following solutions was injected intra-articularly in a double-blind manner. ${ }^{16}$ The solutions did not contain adrenaline. Tourniquet release followed 10 minutes after the intraarticular injection, during which time the dressing was applied to the knee. This was injected intraarticularly at the end of the arthroscopic surgery by the operating surgeon. The patient, the operating surgeon, the anaesthesiologist conducting the case and the nursing staff who assessed the pain and delivered rescue medication were blinded regarding the drug used.

\section{Anaesthetic Technique and Performance}

All patients were pre-medicated with $\mathrm{H} 2$ blocker (Ranitidine $150 \mathrm{mg}$ ) and benzodiazepine (Alprazolam $0.5 \mathrm{mg}$ ).

Postoperative pain intensity was assessed by visual analogue scale, which is a " 0 to 10 " $\mathrm{cm}$ scale with score 0 as "No Pain," up to 3 mild bearable pain, "3 to 5" as "Moderate Pain," greater than " 5 " as "Severe Pain" and " 10 " as "Worst Pain." All patients were explained about VAS before surgery and written informed consent was obtained.

After shifting the patient to operation theatre, an 18-G intravenous cannula was secured and connected to intravenous fluid. Pre-induction monitoring included pulseoximeter, non-invasive blood pressure monitoring and continuous electrocardiography. Injection midazolam $1 \mathrm{mg}$ and injection glycopyrrolate $0.01 \mathrm{mg} / \mathrm{kg}$ was administered intravenously. After pre-oxygenation for 3 minutes with $100 \%$ oxygen, anaesthesia was induced with injection fentanyl 2 $\mathrm{mcg} / \mathrm{kg}$ and injection propofol $2 \mathrm{mg} / \mathrm{kg}$ intravenously for all three groups. After loss of consciousness and eyelash reflex, appropriate size Laryngeal Mask Airway (LMA) was placed. After confirming proper placement of LMA, patient's ventilation was assisted or left breathing spontaneously if found satisfactory with continuous capnography monitoring. Oxygen, nitrous oxide combination was administered in 1:2 ratios with isoflurane $0.6 \%$ to $2 \%$ concentration throughout the procedure. Further analgesics or sedative medications were given for the duration of the procedure if found required. At the end of the surgical procedure before tourniquet was released, the surgeon injected study drug intra-articularly and patient was extubated.

\section{Pain Assessment and Data Collection}

Post-operative pain intensity scores and haemodynamic data (Heart rate and blood pressure) were recorded 15 mins. after extubation and noted as the score at 0 hour; further pain scores were recorded at 1, 2, 4 and 8 hours by the bedside nursing staff who was explained about visual analogue scale and rescue analgesia. Any VAS $>3$ were given injection tramadol $50 \mathrm{mg}$ intravenously as rescue analgesia. The staff recorded the time of first rescue analgesia and total dose of rescue analgesia during 8 hours. Side effects like nausea, vomiting, pruritus, urinary retention and respiratory depression were specifically looked for during the observation period.

\section{Statistical Methodology}

The study sample size was determined to be at least 18 patients in each of the 3 groups studied, which would provide $80 \%$ power for detecting a significant difference in analgesic effect. The student t-test was used both to assess homogeneity and to compare the main results and to find difference between the groups for continuous variables. Data were analysed using SPSS 11.0 software. A descriptive statistical tool, such as mean was used to represent the continuous data. Differences within the groups were analysed using analysis (ANOVA) of variance and Post Hoc test was used to test the difference between individual groups. Chi-Square test was used to find out the association between categorical variables. In all cases, the level of statistical significance ( $P$ value) was less than 0.05 .

\section{OBSERVATIONS AND RESULTS}

During the period of August 2006 and November 2007, 60 patients in age group of 18-65 years were studied. Distribution of patients in each of the 3 groups was similar with respect to demographics, diagnosis and operative procedures.

\section{Age and Sex Distribution}

The mean age in the study population was 35 years. The age comparison was done by student ' $\mathrm{t}$ ' test, which demonstrated no significant difference in its distribution among 3 groups.

\begin{tabular}{|c|c|c|c|}
\hline \multicolumn{4}{|c|}{ Group (No. of Patients) } \\
\hline & $\begin{array}{c}\text { A } \\
\text { (Buprenorphine) }\end{array}$ & $\begin{array}{c}\text { B } \\
\text { (Morphine) }\end{array}$ & $\begin{array}{c}\text { C } \\
\text { (Placebo) }\end{array}$ \\
\hline $\begin{array}{c}\text { AGE } \\
\text { (Years) }\end{array}$ & $36.4+/-11.9$ & $36.8+-12.0$ & $\begin{array}{c}34.0+/- \\
10.4\end{array}$ \\
\hline \multicolumn{4}{|c|}{ Table 1: Age Distribution Among 3 Groups } \\
\hline
\end{tabular}


Sex Distribution

\begin{tabular}{|c|c|c|c|}
\hline \multicolumn{4}{|c|}{ Group (No. of Patients) } \\
\hline SEX & $\begin{array}{c}\text { A } \\
\text { (Buprenorphine) }\end{array}$ & $\begin{array}{c}\text { B } \\
\text { (Morphine) }\end{array}$ & $\begin{array}{c}\text { C } \\
\text { (Placebo) }\end{array}$ \\
\hline F & 3 & 5 & 3 \\
\hline M & 17 & 15 & 17 \\
\hline \multicolumn{3}{|c|}{ Table 2: Sex Distribution Among 3 Groups } \\
\hline
\end{tabular}

\section{Surgery}

\begin{tabular}{|c|c|c|c|}
\hline \multicolumn{5}{|c|}{ Group (No. of Patients) } \\
\hline Surgery & $\begin{array}{c}\text { A } \\
\text { (Buprenorphine) }\end{array}$ & $\begin{array}{c}\text { B } \\
\text { (Morphine) }\end{array}$ & $\begin{array}{c}\text { C } \\
\text { (Placebo) }\end{array}$ \\
\hline $\begin{array}{c}\text { ACL } \\
\text { Reconstruction }\end{array}$ & 11 & 10 & 13 \\
\hline Meniscectomy & 6 & 3 & 5 \\
\hline $\begin{array}{c}\text { Partial } \\
\text { Meniscectomy }\end{array}$ & 0 & 2 & 0 \\
\hline Synovectomy & 3 & 5 & 2 \\
\hline \multicolumn{4}{|c|}{ Table 3: Surgeries Among 3 Groups } \\
There were no Differences among the Groups in Terms \\
of Age, Sex, ASA Status or Arthroscopic Procedure \\
\hline
\end{tabular}

\section{Comparison of Analgesia}

Visual analogue scores assessed at 0, 1, 2, 4 and 8 hours were compared with chi-square test for statistical difference among the groups.

Visual Analogue Score with Respect to Groups at 0 Hour

\begin{tabular}{|c|c|c|c|}
\hline \multicolumn{4}{|c|}{ Group } \\
\hline VAS & $\begin{array}{c}\text { A } \\
\text { (Buprenorphine) }\end{array}$ & $\begin{array}{c}\text { B } \\
\text { (Morphine) }\end{array}$ & $\begin{array}{c}\text { C } \\
\text { (Placebo) }\end{array}$ \\
\hline 0 & 20 & 20 & 0 \\
\hline 3 & 0 & 0 & 6 \\
\hline 4 & 0 & 0 & 7 \\
\hline 5 & 0 & 0 & 4 \\
\hline 6 & 0 & 0 & 3 \\
\hline \multicolumn{3}{|c|}{ Table 4: VAS at O Hour } \\
\hline
\end{tabular}

\begin{tabular}{|c|c|c|c|}
\hline \multicolumn{4}{|c|}{ Group } \\
\hline & $\begin{array}{c}\text { A } \\
\text { (Buprenorphine) }\end{array}$ & $\begin{array}{c}\text { B } \\
\text { (Morphine) }\end{array}$ & $\begin{array}{c}\text { C } \\
\text { (Placebo) }\end{array}$ \\
\hline VAS $<3$ & 20 & 20 & 6 \\
\hline VAS $>3$ & 0 & 0 & 14 \\
\hline \multicolumn{3}{|c|}{ Table 5: Comparison of Analgesia at 0 Hour } \\
\hline
\end{tabular}

VAS $<3$ - Adequate analgesia, VAS $>3$ - Inadequate analgesia.

Mean visual analogue scores analysed during the 0 hour were lower (VAS-0) in A and B groups, when compared to group (C) (Table 5). There was statistically significant difference among 3 groups with respect to VAS at 0 hour (p0.000 ). Pain intensity scores were higher in group (C) when compared with other 2 groups. However, there was no statistical difference among A and B groups (p-0.944). All placebo group patients received rescue analgesia during 0 hour (VAS >3), which indicated inadequate analgesia while none in other 2 drug groups.

Visual Analogue Score with Respect to Groups at 1 Hour

\begin{tabular}{|c|c|c|c|}
\hline \multicolumn{4}{|c|}{ GROUP } \\
\hline VAS & $\begin{array}{c}\text { A } \\
\text { (Buprenorphine) }\end{array}$ & $\begin{array}{c}\text { B } \\
\text { (Morphine) }\end{array}$ & $\begin{array}{c}\text { C } \\
\text { (Placebo) }\end{array}$ \\
\hline 0 & 20 & 20 & 0 \\
\hline 3 & 0 & 0 & 7 \\
\hline 5 & 0 & 0 & 10 \\
\hline 6 & 0 & 0 & 2 \\
\hline 7 & 0 & 0 & 1 \\
\hline \multicolumn{4}{|c|}{ Table 6: VAS at 1 Hour } \\
\hline
\end{tabular}

\begin{tabular}{|c|c|c|c|}
\hline \multicolumn{4}{|c|}{ Group } \\
\hline & $\begin{array}{c}\text { A } \\
\text { (Buprenorphine) }\end{array}$ & $\begin{array}{c}\text { B } \\
\text { (Morphine) }\end{array}$ & $\begin{array}{c}\text { C } \\
\text { (Placebo) }\end{array}$ \\
\hline VAS $<3$ & 20 & 20 & 7 \\
\hline VAS $>3$ & 0 & 0 & 13 \\
\hline \multicolumn{2}{|c|}{ Table 7: Comparison of Analgesia at 1 Hour } \\
\hline
\end{tabular}

Visual analogue scores compared at 1 hour (Table 6) had high scores in placebo in comparison with A and B groups. There was significant difference ( $p-0.000)$ between placebo and the drug groups. However, there was no significant difference ( $p-0.944)$ between the two drug groups (A and B).

Visual Analogue Score with Respect to Groups at 2 Hours

\begin{tabular}{|c|c|c|c|}
\hline \multicolumn{4}{|c|}{ GROUP } \\
\hline VAS & $\begin{array}{c}\text { A } \\
\text { (Buprenorphine) }\end{array}$ & $\begin{array}{c}\text { B } \\
\text { (Morphine) }\end{array}$ & $\begin{array}{c}\text { C } \\
\text { (Placebo) }\end{array}$ \\
\hline 0 & 20 & 8 & 0 \\
\hline 1 & 0 & 7 & 0 \\
\hline 2 & 0 & 5 & 0 \\
\hline 3 & 0 & 0 & 8 \\
\hline 4 & 0 & 0 & 9 \\
\hline 5 & 0 & 0 & 1 \\
\hline 6 & 0 & 0 & 1 \\
\hline 7 & 0 & 0 & 1 \\
\hline \multicolumn{4}{|c|}{ Table 8: VAS at 2 Hours } \\
\hline
\end{tabular}

\begin{tabular}{|c|c|c|c|}
\hline \multicolumn{4}{|c|}{ Group } \\
\hline & $\begin{array}{c}\text { A } \\
\text { (Buprenorphine) }\end{array}$ & $\begin{array}{c}\text { B } \\
\text { (Morphine) }\end{array}$ & C (Placebo) \\
\hline VAS $<3$ & 20 & 20 & 8 \\
\hline VAS $>3$ & 0 & 0 & 12 \\
\hline \multicolumn{3}{|c|}{ Table 9: Comparison of Analgesia at 2 Hours } \\
\hline
\end{tabular}

At $2^{\text {nd }}$ hour VAS score (Table 8) showed significant difference between placebo and other two groups ( $p-0.000)$ Pain intensity scores was significantly different $(p-0.002)$ between group A and B. Even though morphine had significant $\mathrm{p}$ values when compared to buprenorphine, none of the patients received rescue analgesia (Table 9).

Visual Analogue Score with Respect to Groups at 4 Hours

\begin{tabular}{|c|c|c|c|}
\hline \multicolumn{4}{|c|}{ Group } \\
\hline VAS & $\begin{array}{c}\text { A } \\
\text { (Buprenorphine) }\end{array}$ & $\begin{array}{c}\text { B } \\
\text { (Morphine) }\end{array}$ & $\begin{array}{c}\text { C } \\
\text { (Placebo) }\end{array}$ \\
\hline 0 & 20 & 2 & 0 \\
\hline 1 & 0 & 2 & 0 \\
\hline 2 & 0 & 4 & 0 \\
\hline 3 & 0 & 6 & 10 \\
\hline 4 & 0 & 6 & 5 \\
\hline 5 & 0 & 0 & 4 \\
\hline 6 & 0 & 0 & 1 \\
\hline 7 & 0 & 0 & 0 \\
\hline 8 & 0 & 0 & 0 \\
\hline \multicolumn{4}{|c|}{ Table 10: Visual Analogue Score at 4 Hours } \\
\hline
\end{tabular}

\begin{tabular}{|c|c|c|c|}
\hline \multicolumn{4}{|c|}{ Group } \\
\hline & $\begin{array}{c}\text { A } \\
\text { (Buprenorphine) }\end{array}$ & $\begin{array}{c}\text { B } \\
\text { (Morphine) }\end{array}$ & $\begin{array}{c}\text { C } \\
\text { (Placebo) }\end{array}$ \\
\hline VAS $<3$ & 20 & 14 & 10 \\
\hline VAS $>3$ & 0 & 6 & 10 \\
\hline \multicolumn{2}{|c|}{ Table 11: Comparison of Analgesia at 4 Hours }
\end{tabular}


At 4 hours, there was significant difference with respect to VAS score among all 3 groups (Table 10). Placebo had high scores ( $p-0.000)$. A and B groups differed significantly as 6 patients (morphine) (p-0.04), had inadequate analgesia with VAS $>3$.

Visual Analogue Score with Respect to Groups at 8 Hours

\begin{tabular}{|c|c|c|c|}
\hline \multicolumn{4}{|c|}{ Group } \\
\hline$\sum_{j}^{\infty}$ & 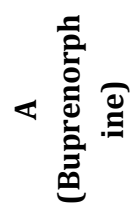 & 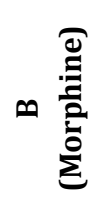 & ن \\
\hline 0 & 14 & 0 & 0 \\
\hline 1 & 3 & 0 & 0 \\
\hline 2 & 3 & 0 & 0 \\
\hline 3 & 0 & 4 & 12 \\
\hline 4 & 0 & 10 & 5 \\
\hline 5 & 0 & 5 & 3 \\
\hline 6 & 0 & 1 & 2 \\
\hline 7 & 0 & 0 & 0 \\
\hline \multicolumn{4}{|c|}{ Table 12: VAS at 8 Hours } \\
\hline
\end{tabular}

\begin{tabular}{|c|c|c|c|}
\hline \multicolumn{4}{|c|}{ Group } \\
\hline & $\begin{array}{c}\text { A } \\
\text { (Buprenorphine) }\end{array}$ & $\begin{array}{c}\text { B } \\
\text { (Morphine) }\end{array}$ & $\begin{array}{c}\text { C } \\
\text { (Placebo) }\end{array}$ \\
\hline VAS $<3$ & 20 & 4 & 10 \\
\hline VAS $>3$ & 0 & 16 & 10 \\
\hline \multicolumn{2}{|c|}{ Table 13: Comparison of Analgesia at 8 Hours } \\
\hline
\end{tabular}

At 8 hours, $P$ values were significantly different among 3 groups. Placebo was significantly different ( $p-0.000)$ from A and B groups in terms of VAS score (Table 12). However, the number of patients with inadequate analgesia (VAS $>3$ ) was same in morphine and placebo group (Table 13). VAS score in morphine group showed significant difference when compared to buprenorphine (Table 13). After rescue analgesia, placebo group had 10 patients with VAS $>3$. This was significant difference among groups.

\section{Heart Rate with Respect to Groups from 0 to 8 Hours}

\begin{tabular}{|c|c|c|c|}
\hline \multicolumn{4}{|c|}{ MAP mmHg (Mean +/- Std Deviation) } \\
\hline$\underset{\Xi}{\mathbb{E}}$ & 《芭 & ص & ن \\
\hline Hour-0 & $75.15+/-8.9$ & $75.15+/-7.3$ & $80.05+/-5.9$ \\
\hline Hour-1 & $72.05+/-7.1$ & $72.25+/-4.8$ & $86.55+/-4.6$ \\
\hline Hour-2 & $71.45+/-5.5$ & $75.5+/-4.7$ & $88.45+/-4.2$ \\
\hline Hour-4 & $70.60+/-4.4$ & $78.75+/-5.2$ & $83.25+/-5.0$ \\
\hline Hour-8 & $71.45+/-4.7$ & $84.6+/-5.6$ & $84.65+/-4.0$ \\
\hline
\end{tabular}

Mean Arterial Pressure with Respect to Groups from 0 to 8 Hours.

\begin{tabular}{|c|c|c|c|}
\hline \multicolumn{4}{|c|}{ MAP mmHg (Mean +/- Std Deviation) } \\
\hline$\underset{\Xi}{\Xi}$ & 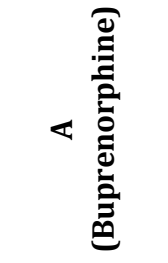 & 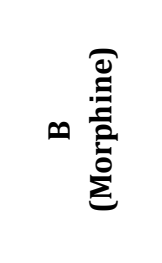 & ن \\
\hline Hour-0 & $89.8+/-7.9$ & $90.4+/-5.5$ & $94.1+/-5.7$ \\
\hline Hour-1 & $87.3+/-6.4$ & $86.8+/-3.9$ & $98.6+/-3.7$ \\
\hline Hour-2 & $88.1+/-6.8$ & $85.2+/-4.0$ & $101.8+/-4.4$ \\
\hline Hour-4 & $91.3+/-7.2$ & $86.3+/-3.4$ & $96.8+/-5.1$ \\
\hline Hour-8 & $95.8+/-7.0$ & $87.2+/-4.2$ & $98.4+/-3.1$ \\
\hline Tabl & $\begin{array}{r}\text { Comparis } \\
\text { from } \\
\end{array}$ & $\begin{array}{l}\text { fMean Arte } \\
\text { o } 8 \text { Hours }\end{array}$ & IPressure \\
\hline
\end{tabular}

Heart rate and MAP was higher in the placebo group when compared to A and B groups (Table 15) throughout observation period and was statistically significant ( $p-0.01)$. Nevertheless, there was no significant difference between the other 2 drug groups ( $p-0.00)$.

\begin{tabular}{|c|c|c|c|c|c|c|c|c|c|}
\hline & \multicolumn{10}{|c|}{ No. of Patients } \\
\hline $\begin{array}{c}\text { Duration } \\
\text { (Hour) }\end{array}$ & $\mathbf{0}$ & $\mathbf{1}$ & $\mathbf{2}$ & $\mathbf{3}$ & $\mathbf{4}$ & $\mathbf{5}$ & $\mathbf{6}$ & $\mathbf{7}$ & $\mathbf{8}$ \\
\hline Buprenorphine & 0 & 0 & 0 & 0 & 0 & 0 & 0 & 0 & 0 \\
\hline Morphine & 0 & 0 & 0 & 0 & 6 & 7 & 5 & 2 & 0 \\
\hline Placebo & 20 & 0 & 0 & 0 & 0 & 0 & 0 & 0 & 0 \\
\hline
\end{tabular}

\begin{tabular}{|c|c|c|}
\hline & $\begin{array}{c}\text { No. of } \\
\text { Patients }\end{array}$ & $\begin{array}{c}\text { Total Dose of } \\
\text { Tramadol in mg }\end{array}$ \\
\hline Buprenorphine & 0 & 0 \\
\hline Morphine & 20 & 1000 \\
\hline Placebo & 20 & 2050 \\
\hline Table 17: Total Dose of Analgesic Received in 8 Hours
\end{tabular}

Table 17: Total Dose of Analgesic Received in 8 Hours

Patients in placebo group had highest dose of rescue analgesia followed by morphine group, while buprenorphine group had none.

None of the patients in any of the group had any of these side effects during the observation period.

\section{DISCUSSION}

The knee is a joint in which arthroscopy has the greatest IA surgical application. There is rich innervation to articular capsule, tendons, ligaments, synovium and periosteum via a mixture of free nerve endings and receptors.

These sensory nerves respond to mechanical stimuli, such as stretching of the joint capsule as well as intra-articular surgical instrumental intervention. Many nerve fibers, for example are non-responsive under normal conditions but react after inflammation, therefore there is a potential for acute injury or inflammation to sensitize nerves such that they respond even when the original stimuli is removed. Hence, just like any other surgical procedure, the arthroscopic intervention of the knee joint can cause considerable postoperative pain that limits ambulation and combined with 
a stress-induced hypercoagulable state, may contribute to an increased incidence of deep vein thrombosis.

Postoperative analgesia following arthroscopic knee surgery can be provided either by systemic administration of narcotic and non-narcotic analgesic drugs. ${ }^{17}$ or IA administration of local anaesthetic drugs. ${ }^{18}$ non-narcotic analgesic drugs (Ketorolac). ${ }^{19}$ and narcotic analgesic drugs (Morphine. ${ }^{20}$ pethidine and fentanyl).

In our study, we sought to evaluate the analgesic efficacy and the need for rescue analgesia with $3 \mathrm{mg}$ morphine and 100 mcg buprenorphine were compared with a placebo $(20 \mathrm{~mL}$ $0.9 \%$ normal saline) when administered intra-articularly following arthroscopic knee surgery.

Various studies compared the analgesic effect of different opioids with different doses. Varrassi G et al21 in their study compared $100 \mathrm{mcg}$ of IA buprenorphine, $50 \mathrm{mg} 0.5 \%$ IA bupivacaine with placebo. They found that $100 \mathrm{mcg}$ buprenorphine or $0.5 \%$ bupivacaine when injected intraarticularly produced good and comparable postoperative pain control and reduced supplementary analgesic requirement.

We found that in immediate postoperative period, i.e. at 0 and 1 hour, buprenorphine and morphine had good and equal analgesic effect as none of the patients required rescue analgesia. In contrast, all 20 patients in placebo group had moderate-to-severe pain and all required supplementary analgesics. These results were similar to Kazemi et al22, Mandal $\mathrm{P}$ et al ${ }^{23}$, Varrassi et al and Varkel et al studies.

Further comparing the analgesic efficacy at 2 and 4 hours postoperatively, all 20 patients had no pain in buprenorphine group indicating good analgesic effect. Even though morphine provided analgesia, 12 patients had mild pain but did not require rescue medication. This was similar to study by Rosseland et $\mathrm{al}^{24}$ who concluded that postoperative analgesic effect of IA morphine was found only in subgroup of patients with higher pain intensity in the immediate post-anaesthetic period. The possible reasons quoted were lack of inflammation that was prerequisite for peripheral opioid analgesia, lack of expression of opioid receptors and due to weak pain stimulus. This could be explained with its partial agonist action, high receptor affinity and slow dissociation.

At 8 hours morphine did not differ much in analgesic action from that of placebo group as all 20 patients had inadequate pain relief and required supplementary analgesics. This was similar to the conclusion drawn by Heard et al 12 who considered IA morphine no better than placebo, except for prolonging the time of first analgesic request and for its systemic effect. Buprenorphine had longer duration of analgesia with less pain scores and no rescue analgesic requirement when compared to morphine. This was consistent with the study by Varrassi et al studies and efficacy of buprenorphine could be related to a local peripheral action as suggested by Stein $\mathrm{C}$ et al.

We compared the haemodynamic data in which the placebo group had higher heart rate and mean arterial pressure than the other two drug groups and this was statistically significant. This could be due to pain and anxiety causing sympathetic stimulation. However, no significant difference with haemodynamic data among the two drug groups.

We also noted the time of request for first rescue analgesia with placebo group requiring analgesics in the immediate postoperative period, six patients required first rescue analgesia at $4^{\text {th }}$ hour of observation in morphine group and none in buprenorphine group.

The total dose of analgesic consumption was highest dose in placebo and morphine group, while buprenorphine group hardly required any analgesic dose.

None of them in two drug groups had any significant side effects during 8-hour observation period.

\section{CONCLUSION}

In summary, this study demonstrated that for eight hours postoperatively $100 \mathrm{mcg}$ buprenorphine provided superior post-operative analgesia to that of $3 \mathrm{mg}$ morphine.

\section{REFERENCES}

1. Stein C, Comisel K, Haimerl E, et al. Analgesic effect of intraarticular morphine after arthroscopic knee surgery. N Engl J Med 1991;325(16):1123-6.

2. Likar R, Schafer M, Paulak F, et al. Intraarticular morphine analgesia in chronic pain patients with osteoarthritis. Anesth Analg 1997;84(6):1313-7.

3. Joshi GP, McCarroll SM, Cooney CM, et al. Intra-articular morphine for pain relief after knee arthroscopy. J Bone Joint Surg Br 1992;74(5):749-51.

4. Joshi GP, McCarroll SM, O'Brien TM, et al. Intraarticular analgesia following knee arthroscopy. Anesth Analg 1993;76(2):333-6.

5. Dalsgaard J, Felsby S, Juelsgaard P, et al. Low-dose intraarticular morphine analgesia in day case knee arthroscopy: a randomized double-blinded prospective study. Pain 1994;56(2):151-4.

6. Allen GC, St Amand MA, Lui AC, et al. Post-arthroscopy analgesia with intraarticular bupivacaine/morphine a randomized clinical trial. Anesthesiology 1993;79(3):475-80.

7. Heine MF, Tillet ED, Tsueda $\mathrm{K}$, et al. Intra-articular morphine after arthroscopic knee operation. Br J Anaesth 1994;73(3):413-5.

8. McSwiney MM, Joshi GP, Kenny P, et al. Analgesia following arthroscopic knee surgery. A controlled study of intraarticular morphine, bupivacaine or both combined. Anaesth Intensive Care 1993;21(2):201-3.

9. Laurent SC, Nolanf JP, Pozo JL, et al. Addition of morphine to intra-articular bupivacaine does not improve analgesia after day-case arthroscopy. Br J Anaesth 1994;72(2): 170-3.

10. Khoury GF, Chen AC, Garland DE, et al. Intraarticular morphine, bupivacaine, and morphine/bupivacaine for pain control after knee videoarthroscopy. Anesthesiology 1992;77(2):263-6.

11. Raja SN, Dickstein RE, Johnson CA. Comparison of postoperative analgesic effects of intraarticular bupivacaine and morphine following arthroscopic knee surgery. Anesthesiology 1992;77(6):1143-7.

12. Heard SO, Edwards WT, Ferrari D, et al. Analgesic effect of intraartictdar bupivacaine or morphine after arthroscopic knee surgery: a randomized, prospective, double-blind study. Anesth Analg 1992;74(6):822-6.

13. Badner $\mathrm{NH}$, Bourne $\mathrm{RB}$, Rorabeck $\mathrm{CH}$, et al. Addition of morphine to intra-articular bupivacaine does not improve analgesia following knee joint replacement. Reg Anesth 1997;22(4):347-50. 
14. Kalso E, Trainer MR, Carroll D, et al. Pain relief from intraarticular morphine after knee surgery: a qualitative systematic review. Pain 1997;71(2):127-34.

15. Dierking GW, Ostergaard HT, Dissing CK, et al. Analgesic effect of intra-articular morphine after arthroscopic meniscectomy. Anaesthesia 1994;49(7):627-9.

16. Varkel V, Volpin G, Ben-David B, et al. Intra-articular fentanyl compared with morphine for pain relief following arthroscopic knee surgery. Canadian Journal of Anaesthesia 1999;46(9):867-71.

17. Reuben SS, Sklar J. Pain management in patient who undergo outpatient arthroscopic surgery of the knee. The Journal of Bone and Joint Surgery 2000;82A(12):1754-66.

18. Gupta A, Axelsson K, Allvin R, et al. Postoperative pain following knee arthroscopy: the effects of intra-articular ketorolac and /or morphine. Regional Anaesthesia Pain Medicine 1999;24(3):225-30.

19. Likar R, Kapral S, Steinkellner H. Dose dependency of intra-articular morphine analgesia. British Journal of Anaesthesia 1999;83(2):241-4.
20. Boas RBV, Villiger JW. Clinical actions of fentanyl and buprenorphine. The significance of receptor binding. British Journal of Anaesthesia 1985;57(2):192-6.

21. Varrassi GF, Marinangeli A, Ciccozzi G, et al . Intra-articular buprenorphine after knee arthroscopy. Act Anaesthesiologica Scandinavica 1999;43(1):51-5.

22. Kazemi AP, Rezazadeh S, Gheracheh HR. Intra-articular sufentanil compared to morphine for pain relief after arthroscopic knee surgery. Journal of Research in Medical Sciences 2004;4:168-72.

23. Mandal P, Saudagar AH. Intra-articular fentanyl for analgesia following arthroscopic knee surgery. Indian Journal of Anaesthesia 2002;46(2):107-10.

24. Rosseland LA, Stubhaug A, Skoglund A, et al. Intraarticular morphine for pain relief after knee arthroscopy. Acta Anaesthesiologica Scandinavica 1999;43(3):252-7. 